\title{
The Influence of Narcissism on Intensity of Instagram Use in Generation Z
}

\author{
Yuliana Suzuki Lengkong ${ }^{1}$ Fransisca Iriani R. Dewi ${ }^{1}$
}

\author{
${ }^{1}$ Faculty of Psychology, Universitas Tarumanagara, Jakarta 11440, Indonesia \\ *Corresponding author. Email: fransiscar@fpsi.untar.ac.id
}

\begin{abstract}
In this digital era, information can be easily accessed through features on social media, especially Instagram. Instagram has gained wide popularity among teenagers, especially towards generation $\mathrm{Z}$, who have known technology from an early age. This study aims to find out whether the intensity of Instagram social media use has an influence on the level of narcissism in generation Z. A total of 384 active Instagram users in Indonesia completed an online survey within age range of 10 years - 25 years (generation $Z$ ). The study used intensity of Instagram use made by Taqwa (2018) and Narcisstic Personality Inventory- Likert version (NPI-L) developed by Gentile (2013). The study used simple linear regression to predict the effect of narcissism on intensity of Instagram use in generation $\mathrm{Z}$. The results of the linear regression analysis showed that there was an influence of $3.9 \%$ and $96.1 \%$ is influenced by other factors.
\end{abstract}

\section{Keywords: Intensity of social media use, narcissism, Instagram, Generation Z}

\section{INTRODUCTION}

The millennials are no longer at the stage of adolescent, but today's adolescents are the Generation Z. Generation Z were born between 1995- 2010 [1]. Generation Z spends an average of 6.5 hours a day on social media, it's not a surprise that technology has become part of their culture. In Indonesia, based on the data collected by Hootsuite and We are Social shows that the highest use of technology falls to a group population of 13 years and over with $77 \%$ (210 million) of the total population ( 272 million) in 2020 [2]. This shows the influence of the use of social media in Generation $\mathrm{Z}$ is high. The increased intensity of social media use show that some trends in narcissism can occur.

\subsection{Related Work}

\subsubsection{Intensity of Instagram Use}

Intensity of Instagram use is the amount of effort put into accessing Instagram. The amount of effort can be defined as energy, time, and energy in carrying out activities around social media. In this case, Instagram facilitates the attitudes and behaviours shown by Instagram users.

There are two factor models that influence the intensity of Instagram use [3]. The first factor is the need to have. This need is related to the desire to have a sense of belonging and acceptance. The second factor is the need for selfpresentation, individual efforts to build other people's perspectives on it.

Other additional factors people are using Instagram as a form of distraction motive, stalking others and expanding social interaction [4][5]. Previous research found that age affects the intensity of social media use. The largest users of social media are young adults (18-24 years old). The recent research also showed that social media is mostly used by young adults [2]. Not many studies have examined the phenomenon of social media use in generation $\mathrm{z}$ so this research was conducted to provide an overview of generation $\mathrm{Z}$ who use Instagram in Indonesia.

\subsubsection{Intensity of Instagram Use and Narcissism}

Various kinds of features on Instagram allow users to build self-representations that look ideal and emphasize the salient features (both in terms of physicality, strengths, achievements, etc.) in themselves to gain recognition from others [6].Thus, selfie behaviour in social media has also increased [7][5][8]. Selfie is believed as one of the narcissistic behaviour that contribute in promoting narcissistic behaviour [8]. This is because image-based social media accentuates a form of self-representation that is stronger than other types of social media.

Apart from selfies, the number of friendships and posts are also considered as narcissistic behaviour [9]. Individuals with narcissism tend to have more number of friends and posts due to high frequent time of posting.

Several previous studies have examined the relationship between narcissism and activities on social media. A high correlation of narcissism was found between the frequency of posting selfie images with attention-seeking motivation [10]. The research is also consistent that individual narcissism has a relationship with self-promoting behaviour and time spent editing photos to create attractive selfimages [11][12]. 
Previous research found that the millennial generation is more likely to show the dimensions of exhibitionism and self-promotion behaviour [13]. This finding attracted the attention of researchers in researching generation $\mathrm{Z}$ considering that generation $\mathrm{Z}$ understands more about technology and social media than previous generations.

\subsection{Our Contribution}

This paper is intended to provide an overview of Instagram use and the level of narcissism of generation $\mathrm{Z}$ in Indonesia. This paper is aim to examining the effect of narcissism on the intensity of Instagram social media use in generation $\mathrm{Z}$.

\subsection{Paper Structure}

This paper is divided into four sections. Section 1 consist of research background and the goal of this study. In Section 2 (Methods), participants of the study, measurement used, data analysis plan is discussed. Section 3 presents the analysis result and findings of this study, and its implication. Lastly, Section 4 presents the conclusion of this paper as well as direction for future research.

\section{BACKGROUND}

\subsection{Participants}

The numbers of participants involved in this study are 384 people with birth ranges from 1995 to 2010. Based on the demographic data of the participants, most participants were 21 years old $(28.4 \%)$. The mean age of the participants was 20.68 years $(\mathrm{SD}=2,524)$. Most of the participants are students $(77.7 \%)$ than other work statuses. The majority of participants are domiciled in Jakarta (31.5\%), followed by others located outside the Jabodetabek area $(25.8 \%)$. Table 1 shows a descriptive analysis of the profile of the participants involved in the study

\subsection{Measurements}

\subsubsection{Intensity of Instagram Use}

The intensity of Instagram use is taken from a measuring tool made by Taqwa [1]. However, the original measuring tool which is intensity of using Instagram stories was changed to Instagram alone to align with the research focus. The questionnaire contains 12 items using 4-point Likert scale. There are four aspects measured in the study: attention, appreciation, duration and frequency). The assignment of each item depends on the type of statement. If the statement is positive, the highest score is the maximum score which is 4 . In contrast to the negative statement, the highest score is the minimum score which is 1. In addition, in measuring time spent in accessing Instagram is given several multiple answer choices. The amount of Cronbach's alpha is 0.77 .

\subsubsection{NPI-L}

Narcissism is measured using modified version of the Narcissistic Personality Inventory-Likert Version (NPI-L) scale developed by Gentile (2013). The NPI aims to measure seven aspects of narcissistic behaviour, namely authority, self-sufficiency, entitlement, exhibitionism, exploitativeness, and vanity which consists of 35 items (Raskin \& Terry, 1988). The original version was using force choice (NPI-FC) response options while the modified version used a 5-point Likert scale with a range of 1 : "strongly disagree", 5: "strongly agree". The amount of Cronbach's alpha is 0.89 .

\subsection{Data Analysis}

The data is processed using the Statistical Product and Service Solutions (SPSS) program. In quantitative data processing, there are four stages that are carried out before data analysis. The first stage is to match the number of items collected according to the number of participants involved. After that, it is continued with the improvement stage to check the completeness of filling in the data from the completeness of the answers and the participant's personal data. Data that do not meet the research criteria will not be used in data analysis. Furthermore, the identification is carried out specifically including the identity of the respondent in SPSS. Then giving codes to classify respondent's answers. After classifying the data, a simple linear regression analysis was performed. Simple linear regression test to determine the linear relationship between intensity of social media use of Instagram (Y) as a criterion and narcissism $(\mathrm{X})$ as a predictor variable. 
Table 1 Profile of Participants

\begin{tabular}{|c|c|c|c|c|c|}
\hline Characteristics & $\mathrm{N}=384$ & $\begin{array}{c}\text { Percentage } \\
(\%)\end{array}$ & Characteristics & $\mathrm{N}=384$ & $\begin{array}{c}\text { Percentage } \\
(\%)\end{array}$ \\
\hline Age & & & Work Status & & \\
\hline $10-13$ & 9 & 2.4 & Student & 296 & 77.1 \\
\hline $14-17$ & 31 & 8.0 & Private Employees & 50 & 13.0 \\
\hline $18-21$ & 212 & 55.2 & Self-Employees & 15 & 3.9 \\
\hline $22-25$ & 132 & 34.3 & Others & 23 & 6.0 \\
\hline \multirow[t]{9}{*}{15} & 4 & 1.0 & Domicile & & \\
\hline & & & Jakarta & 121 & 31.5 \\
\hline & & & Bogor & 23 & 6.0 \\
\hline & & & Depok & 18 & 4.7 \\
\hline & & & Tangerang & 43 & 11.2 \\
\hline & & & Bekasi & 80 & \\
\hline & & & & \multirow{2}{*}{\multicolumn{2}{|c|}{20.8}} \\
\hline & & & Others & & \\
\hline & & & & \multicolumn{2}{|r|}{25.8} \\
\hline
\end{tabular}

\section{FINDINGS AND DISCUSSIONS}

Overall data also shows that the majority of generations $\mathrm{Z}$ are classified as moderate users. Based on the results of the study, it was found that generation $\mathrm{Z}$ is a moderate user of Instagram social media with a percentage value of $67.2 \%$. But even though the intensity of Instagram social media users in generation $\mathrm{Z}$ is moderate, this still shows involvement in the use of social [14]. This moderate level is also relevant to the average results of the dimensions of the intensity of the use of Instagram social media. Generation Z has a high frequency of opening Instagram per day but low appreciation. This explains that generation $\mathrm{Z}$ is not easily influenced by information on Instagram. Although the motivation to use Instagram social media in generation $\mathrm{Z}$ was not carried out previous study showed that highest motivation to use Instagram is due to spending time when bored [6]. The findings of this study can provide an idea why the dimension of appreciation in generation $\mathrm{Z}$ is low. For measuring narcissism, it shows that the majority of subjects are at a moderate level of narcissism with a percentage value of $78.9 \%$. The result of descriptive statistics for the dimensions of narcissism shows that selfsufficiency has the highest average score. The dimension of exhibitionism in narcissism shows a low mean result. The self-sufficiency dimension shows high average results. The self-sufficiency dimension has a relationship with an independent attitude, assertiveness, self-confidence and the need for achievement [15]. This means that narcissistic behavior in Generation $\mathrm{Z}$ does not have a negative impact on real life and is still can be considered as a normal narcissistic trait. On the other hand, exhibitionism dimension shows a lack of self-control, attention seeking and extraversion. It can be concluded that the nature of narcissism in generation $\mathrm{Z}$ is still classified as positive narcissism.
Narcissism is not always associated with negative things. Positive behavior in narcissism has positive social traits, healthy self-esteem, self-confidence and well-being that will encourage individuals to achieve success [16]. However excessive narcissism can lead to negative narcissism such as arrogance and selfishness. Excessive narcissism can also lead to addiction in social media but was not done in this study [9].

Kolmogorov-Smirnov normality test was carried out using unstandardized residual value (RES_1). Based on the results of the SPSS output, it shows that the significance value of Asymp. Sig (2-tailed) is 0.200 greater than 0.05 which means the data is normally distributed. The author also carried out linearity based on the results of the deviation from linearity. The results of the linearity test obtained a deviation from linearity value of 0.134 meaning there is a significant linear relationship between narcissism towards intensity of Instagram use.

In the classic assumption test of the regression model, a good regression model is the absence of heteroscedastic symptoms. The heteroscedasticity test is conducted to find out whether there is an inequality of variance or residuals between the data. There are several ways to do the heteroscedasticity test, the author chose to do the heteroscedasticity test using a scatterplot image. The scatterplot image shows that there are no symptoms of heteroscedastic problems. Thus, it can be concluded that the regression model is already being fulfilled.

The significance value test was carried out to determine the significance level of the regression obtained a significance value of 0.000 , which means the significance

value is smaller than 0.05 . Thus, it can be concluded that the regression equation model is significant.

After all the assumption tests are fulfilled, hypothesis test is conducted. The hypothesis test uses the simple linear regression test between the intensity of Instagram use with narcissism. Based on the result of analysis, a regression 
coefficient value of 0.198 was obtained. The results of the analysis also obtained $\mathrm{R}$ Square value which is 0.039 which means the influence of narcissism towards intensity of Instagram use is only $3.9 \%$ with the rest $96.1 \%$ influenced by other variables. In addition, the calculated $\mathrm{F}$ value $=$ 15.658, $\mathrm{p}=0.000(<0.05)$ which means narcissism have significant role towards intensity of Instagram use. The value of $t$ count $=12.643$ with a significance value $0.000(<$ 0.05). This can be concluded that $\mathrm{H} 0$ is rejected and $\mathrm{H} 1$ is accepted, meaning that narcissism (X) has a positive effect on intensity of Instagram use (Y) by $3.9 \%$. The result of the analysis can be seen in the following table.

Table 2 The Role of Intensity of Instagram Use with Narcissism

\begin{tabular}{lccccc}
\hline $\begin{array}{l}\text { Predictor } \\
\text { Variable }\end{array}$ & $\mathrm{R}$ & $\mathrm{R}^{2}$ & $\mathrm{~F}$ & Sig. & $T$ \\
\hline $\begin{array}{l}\text { Narcissism } \\
\text { towards }\end{array}$ & & & & & \\
$\begin{array}{l}\text { intensity of } \\
\text { Instagram }\end{array}$ & .198 & .039 & 15.658 & .000 & 12.643 \\
use & & & & & \\
\hline
\end{tabular}

\section{CONCLUSIONS}

Based on the results of the data analysis that has been done, it can be concluded that the data on the narcissism variable $(\mathrm{X})$ and the intensity of using Instagram social media (Y) are normally distributed. In addition, there is a linear relationship between the two variables, which means that the higher the intensity of Instagram social media use, the higher the narcissism variable. The regression model is fulfilled and can be used to predict narcissism in generation $\mathrm{Z}$ because there are no symptoms of medical health. There is a positive influence of narcissism on the intensity of using Instagram social media. In other words, narcissism predicts $3.9 \%$ of the intensity of Instagram social media use, and $96.1 \%$ is influenced by other factors.

This study has several limitations. The first is due to the Covid pandemic cases that occurred throughout 2020, so the research process was carried out online. The weakness that the researchers realized was lack of data collected namely gender whereas this could be use as additional information in determining whether man or women who actually have a higher intensity level in using Instagram and determining the level of narcissism.

Another limitation of the study is in classifying the correct generation Z. According to Dwidienawati and Gandasari, generation $Z$ is classified as born in 1993-2005 while Prakashyadav and Rai classified generation Z is born 19912017 [5][16]. However, since this study was conducted in Indonesia, researchers followed the range year of generation Z based on Putra's research which is 1995-2010 [1]. There might be a possibility that there are differences in the intensity of use of social media between births in the 1990 s and 2000s, so this can also be a consideration for further research. Finally, researchers used an inadequate measuring tool in measuring the intensity of Instagram use.
There is a more reliable use of measuring tools in research such as the Facebook Intensity Scale by Ellison in 2007 which have been adapted into various kinds of social media. In addition, further research is expected to use other variables that can affect the level of narcissism in Generation Z, given that the intensity of Instagram use is only $3 \%$. Other types of social media that are often used by generation $\mathrm{Z}$ today such as Tiktok or focusing more on the social media features can be an option. For Instagram users, especially generation $\mathrm{Z}$, it is important to maintain the intensity of Instagram. Although the study did not discuss further regarding the effect of high intensity use, too much of it can cause addiction and other behavioral problems. Apart from some of the limitations of this study, this study has several advantages. The strength of this research is that there are not many studies on the influence of the intensity of the use of Instagram social media on narcissism in the previous generation $\mathrm{Z}$. Second, the results of the study illustrate that the narcissism variable needs to be considered for use in further research if it is related to the effect on the intensity of social media use. In addition, the findings of this study certainly require additional research to examine other roles in the intensity of Instagram social media use in generation $Z$. The findings from this study also help researchers and practitioners to understand the concept of narcissism, especially in this digital era.

\section{REFERENCES}

[1] Taqwa, M. I. (2018). Intensitas penggunaan media sosial instagram stories dengan kesehatan mental. Universitas Muhammadiyah.

[2] Rashid, A., Amir, M., Amad, Z., Sajid, R., Fernando, A., \& Zeb, M. A. (2020). Conceptualization of smartphone usage and feature preferences among various demographics. Cluster Computing, 0123456789. https://doi.org/10.1007/s10586-020-03061-x

[3] Trifiro, B. (2018). Instagram Use and It's Effect on Well-Being and. Master of Arts in Communication, Paper 4.

[4] Althobaiti, R. (2018). The motivations and uses of instagram. Electronic Theses and Disserations. Retrieved from https://dc.etsu.edu/etd/3411

[5] Huang, Y. (2018). Motives for Instagram Use and Topics of Interest among Young Adults. https://doi.org/ 10.3390/fi 10080077

[6] Andreassen, C. S., Pallesen, S., \& Griffiths, M. D. (2017). The relationship between addictive use of social media, narcissism, and self-esteem: Findings from a large national survey. Addictive Behaviors, 64, 287-293. https://doi.org/10.1016/j.addbeh.2016.03.006 
[7] Fox, J., \& Rooney, M. C. (2015). The Dark Triad and trait self-objectification as predictors of men's use and self-presentation behaviors on social networking sites. Personality and Individual Differences, 76, 161-165. https://doi.org/10.1016/j.paid.2014.12.017

[8] Wickel, T. M. (2015). Narcissism and Social Networking Sites: The Act of Taking Selfies. The Elon Journal of Undergraduate Research in Communication, 6(1), 5-12.

[9] Frederick, C., \& Zhang, T. (2019). Narcissism and social media usage: is there no longer a relationship? Journal of Articles in Support of the Null Hypothesis, 16(1).

[10] Weiser, E. B. (2015). \# Me : Narcissism and its facets as predictors of selfie-posting frequency. PAID, 86, 477-481. https://doi.org/10.1016/j.paid.2015.07.007

[11] Jiang, S., \& Ngien, A. (2020). The Effects of Instagram Use, Social Comparison, and Self-Esteem on Social Anxiety: A Survey Study in Singapore. Social Media and Society, 6(2). https://doi.org/10.1177/ 2056305120912488

[12] Moon, J. H., Lee, E., Lee, J. A., Choi, T. R., \& Sung, Y. (2016). The role of narcissism in self-promotion on Instagram. Personality and Individual Differences, 101, 22-25. https://doi.org/10.1016/j.paid.2016.05.042

[13] Bergman, S. M., Fearrington, M. E., Davenport, S. W., \& Bergman, J. Z. (2011). Millennials, narcissism, and social networking: What narcissists do on social networking sites and why. Personality and Individual Differences, 50(5), 706-711. https://doi.org/10.1016/ j.paid.2010.12.022

[14] Prakashyadav, G., \& Rai, J. (2017). The Generation $Z$ and their Social Media Usage: A Review and a Research Outline. (2011). https://doi.org/10.18311/ gjeis/2017/15748

[15] Raskin, R., \& Terry, H. (1988). A principalcomponents analysis of the narcissistic personality inventory and further evidence of its construct validity. Journal of Personality and Social Psychology, 54(5), 890-902.

[16] Spencer, V., Garcia-Simpson, C., \& Newland, S. (2017). Narcissism: the good, the bad and the ugly. Online Submission, 1-9. https://doi.org/10.1017/ CBO9781107415324.004 